Military Technical College Kobry El-Kobbah, Cairo, Egypt.

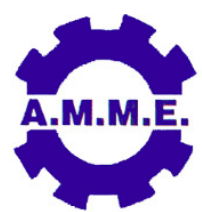

$17^{\text {th }}$ International Conference on Applied Mechanics and Mechanical Engineering.

\title{
LAMINAR BURNING VELOCITY FOR BLENDS OF JOJOBA BIO- GASOLINE WITH BASIC GASOLINE
}

\author{
M.S. Radwan*, I. G. Elgizawy ${ }^{\star \star}$, Y. A. Attai ${ }^{\star \star \star}$ and M. Gamal ${ }^{\star \star \star \star}$
}

\begin{abstract}
In the present work, the laminar burning velocity for different blends of jojoba biogasoline with basic gasoline was measured. For this purpose, a constant volume vessel using transient Pressure technique was designed and manufactured with special criteria on safety and accuracy of the experimental results. The results were obtained for a range of equivalence ratios 0.8-1.3, initial mixture temperatures varying from $350 \mathrm{~K}$ to $450 \mathrm{~K}$ and initial mixture pressures from 0.5 to 1 bar (absolute). The reliability and accuracy of the test facility were confirmed by comparing the acquired burning velocity data for iso-octane with those available in the literature. The laminar burning velocity of different blends was compared to iso-octane and commercial gasolines at the same research octane number. It was found that blends of jojoba bio-gasoline with basic gasoline exhibit lower burning velocities than commercial gasolines and iso-octane fuel, primarily due to its high aromatic content.
\end{abstract}

\section{KEYWORDS}

Laminar burning velocity, Jojoba bio-gasoline, Commercial gasoline, Alternative fuels.

* Professor, Dep. of Mechanical Power, Helwan University, Cairo, Egypt.

** Emeritus professor, Dep. of Mechanical Power, Helwan University, Cairo, Egypt.

*** Assistant prof., Dept. of Mechanical Power, Helwan Univ., Cairo, Egypt.

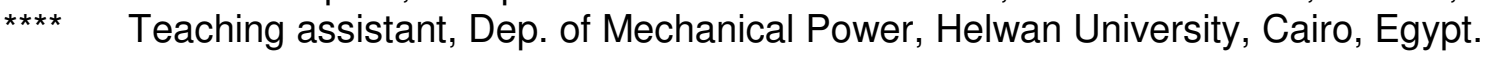




\section{NOMENCLATURE}

$\begin{array}{cl}B G & \text { Boosted gasoline } \\ \mathrm{CG} & \text { Commercial gasoline } \\ \mathrm{P} & \text { Pressure at time } \mathrm{t} \text { at which the laminar burning velocity is computed (in } \\ & \text { the order of } 1.1 \mathrm{Pi} \text { for used model) } \\ \mathrm{P}_{\mathrm{e}} & \text { Thermodynamic equilibrium pressure of the burned gasses } \\ \mathrm{P}_{\mathrm{i}} & \text { Initial mixture pressure before combustion } \\ \mathrm{R} & \text { Bomb radius } \\ \mathrm{RON} & \text { Research octane number } \\ \mathrm{r}_{b} & \text { Radius of the cylinder at any instant after combustion } \\ \mathrm{r}_{\mathrm{i}} & \text { Radius of the cylinder at any instant before combustion } \\ \mathrm{S}_{\mathrm{L}} & \text { Laminar burning velocity } \\ \mathrm{t} & \text { Time } \\ \mathrm{T}_{\mathrm{i}} & \text { Initial mixture temperature before combustion } \\ \mathrm{T}_{\mathrm{u}} & \text { Burned gas temperature } \\ \gamma_{\mathrm{u}} & \text { Specific heat ratio }\end{array}$

\section{INTRODUCTION}

The energy crisis and energy prices are among the most important topics nowadays. Since the substantial source of energy is the petroleum oil. The world's gift of petroleum oil is non-renewable, finite and close to depletion. Worldwide population expansion and industrial extending have drove to a seven-fold increase in petroleum oil consumption in the last 50 years. There is no doubt about the fact that oil production will not meet the need in the near future. When that happens, petroleum oil prices will rise extraordinarily and the global economy will be negatively affected [1-2]. Scientists and engineers are striving to find out an alternative source of energy to replace it. One of these sources is called 'bio-fuels' which can be derived from particular seeds oil. These fuels extent from gasses to liquids and are derived from renewable sources. All of such fuels can be used in a diesel engine or a gasoline engine; however, some require significant modification to the engine or fuel storage and delivery systems [3]. In the prospection for a liquid alternative fuel to fill the gap between supply and consumption, non-edible oil bio-fuels feedstock standing high since they are renewable, carbon dioxide neutral and thereby save the environment in addition to they should not be affected, price wise, by the cost of food oils [4]. It will be discerned that through the non-edible oil feedstock, Jojoba and jatropha rank high in terms of productivity. Although jatropha is being studied as a potentially motivating crop for wet climates and low-quality soils, jatropha oil is very toxic and tumor promoter [5]. Conversely, jojoba is very safe with its many confirmed pharmaceutical and cosmetic applications so the choice of jatropha was ruled out and jojoba was selected instead. The reasons for choosing the jojoba plant for biofuel production in Egypt beside its safety of use were mentioned by Radwan [6].

Jojoba bio-gasoline have been synthesized and examined as an alternative to gasoline fuel in the internal combustion engine $[4,6,13]$. one of the main factors affecting combustion in engines operating on blends of jojoba bio-gasoline with basic gasoline (present work), namely, the laminar burning velocity [7]. 
The laminar burning velocity of the premixed combustible mixture is a function of temperature, pressure, and composition, instantly determines the rate of energy released during combustion in a quiescent gas mixture, and so the burning rate of the mixture, affects the performance of the combustion process in many combustion applications and required to validate and legalize the chemical reaction mechanisms needed for combustion simulations of different devices [11].

Many authors studied the laminar burning velocity for a different alternative fuels. Knorsch et al. [8] investigated experimentally the burning velocity of The butanol isomers as well as ethanol as surrogate fuels or blend components in the future. Sileghem et al. [9] studied the burning velocity of gasoline and some gasoline substitutional components such as iso-octane In addition to n-heptane and toluene by using the heat flux method. Tian et al. [10] measured the laminar burning velocities of 2.5-dimethylfuran besides ethanol and gasoline. It was found that the 2.5-dimethylfuran burning velocity and its high energy density make it as a promising bio-fuel and a possible alternative to gasoline.

The main objective of the current work was to provide an accurate experimental determination of the laminar burning velocity for BGs (blends of Jojoba bio-gasoline with Basic gasoline ) with different RON (90, 92, 95 and 98) and CGs (commercial gasolines) for the same RON (90, 92 and 95$)$ at different initial pressures $\left(\left(\mathrm{P}_{\mathrm{i}}\right)\right.$ from 0.5 bar to 1 bar (absolute)), various equivalence ratios $(\varphi)$ (from 0.8 to 1.3) and different initial temperatures $\left(\mathrm{T}_{\mathrm{i}}\right)$ (from $350 \mathrm{~K}$ to $450 \mathrm{~K}$ ). The composition of jojoba bio-gasoline and basic gasoline fuels are given in Table 1 .

In the present study, the laminar burning velocity of spherical flames in a cylindrical combustion bomb has been determined using the transient pressure measuring technique. The reliability of the present test set-up for giving accurate and precise measurements of the laminar burning velocity have been extensively tested. Isooctane results also have been presented for comparison to the literature. The test measurements covered iso-octane at different conditions.

\section{EXPERIMENTAL FACILITIES}

An experimental facility comprising a constant volume cylindrical bomb was designed and built for the purpose of carrying out a comprehensive experimental program to determine the laminar burning velocity for the blends of Jojoba bio-gasoline with Basic gasoline RON(90, 92, 95 and 98) and commercial gasolines RON(90, 92 and 95). Table 2 shows the characteristics of BGs in comparison with CGs at the same RONs.

\section{Experimental Set-Up}

There are many present measuring techniques to find out the laminar burning velocity. However, many authors have shown that the combustion vessel method that employ either high-speed Schlieren photography or pressure-time history measurement techniques are both versatile and accurate [15,16]. 
The experimental setup is shown in Figure 1. It consists mainly of six units; the combustion bomb, air supply system, fuel evaporation system, the ignition system, mixture heating system, instrumentations and the data processing system. The pressure-time history that follows the ignition of the combustible mixture inside the bomb is recorded on-line. The pressure data is then analyzed to deduce the laminar burning velocity.

The present combustion bomb was an electrically heated thick-walled stainless steel 304 cylinder. The cylindrical chamber was $8 \mathrm{~mm}$ thick, $200 \mathrm{~mm}$ inner diameter and its height was $200 \mathrm{~mm}$. The cylinder was equipped at both ends with two stainless steel 304 flanges each was $12 \mathrm{~mm}$ thick; the first one was used as a cylinder cover holder using 8 bolts and the other one was designed as a stationary cover to cylinder, the covers perform as cylinder heads of the combustion bomb. A piezo-electric pressure transducer was mounted at the body of the bomb through a hole drilled radically on the bottom wall of the bomb to measure the pressure-time history. The bomb section was furnished with a vacuum gauge and a simple pressure gauge, which were fitted to the circumference of the bomb through two ball valves to enable the measurement of the initial pressure of the mixture before combustion and monitor the pressure during combustion. Two orthogonal holes were mounted through the combustion bomb body for composing two ignition spark plugs. An iron-constantan thermocouple was used to determine the initial temperature of the mixture.

\section{Measuring Technique}

The data acquisition includes the subsequent steps:

1. the pressure-time history was measured using a calibrated piezo-electric pressure transducer equipped with a charge amplifier.

2. after amplification, the transducer output (emf) was depicted as a function of time on a personal computer using LabVIEW program. the emf-t signal was then fed to data acquisition card capable of sampling at frequencies up to 65 $\mathrm{kHz}$. The sampling frequency was kept constant at $10 \mathrm{kHz}$ for each experiment.

3. the analog signal was converted to a digital signal, which was emf-t and displayed on the monitor of a personal computer as well as being saved on an excel sheet file.

4. the output-time relation was first converted into a pressure-time data using the calibration curve of the pressure transducer. the laminar burning velocity can be then obtained from the pressure-time history according to Lewis and von Elbe thermodynamic model [17] using the following set of equations relating the burning velocity to the immediate values of both the pressure and the pressure gradient using the early mentioned model:

$$
S_{L}=\left(\frac{d r_{i}}{d t}\right)\left(\frac{r_{i}}{r_{b}}\right)^{2}\left(\frac{P_{i}}{P}\right)^{1 / \gamma_{u}}
$$

where:

$$
\left.r_{i}=R\left[\left(P-P_{i}\right) / P_{e}-P_{i}\right)\right]^{1 / 3}
$$




$$
\begin{aligned}
& d r_{i} / d t=\left(\frac{R}{3\left(P_{e}-P_{i}\right)}\right)\left(\frac{\left(P-P_{i}\right)}{\left(P_{e}-P_{i}\right)}\right)^{\frac{-2}{3}}(d P / d t) \\
& r_{b}=R\left[1-\frac{\left(P_{i} / P\right)\left(T_{u} / T_{i}\right)\left(P_{e}-P\right)}{\left(P_{e}-P_{i}\right)}\right]
\end{aligned}
$$

and

$$
\left(T_{u} / T_{i}\right)=\left(P / P_{i}\right)^{1 / \gamma_{u}}
$$

To obtain $\mathrm{dP} / \mathrm{dt}$ at this point, the pressure-time record in the range $\mathrm{Pi}<\mathrm{P} \leq 1.1 \mathrm{Pi}$ is fitted to a fourth degree polynomial equation using a model submitted by Elbahar [16].

5. from the input data, the adiabatic flame temperature, the enthalpy of formation, the equilibrium pressure and the species concentration are calculated using EES application program proposed by Attia [11].

6. the burning velocity is determined, using equation (1), at sampling points of different time steps within the range $\mathrm{Pi}<\mathrm{P} \leq 1.1 \mathrm{Pi}$. the maximum burning velocity is obtained directly from the results at $P=1.1 \mathrm{Pi}$ according to Lewis and Von Elbe model [17].

\section{Preliminary Experiments}

Preliminary experiments were executed with iso-octane as a reference fuel. Figure 2 shows the effect of equivalence ratio of the isooctane-air mixture on the laminar burning velocity at initial mixture temperature of $358 \mathrm{~K}$ and atmospheric initial pressure. Figure 3 also shows the effect of the mixture initial temperature on the laminar burning velocity at an equivalence ratio of 1 and an initial mixture pressure of 1 bar. Comparison of the burning velocity data obtained with the available data for isooctane in the literature showed a good agreement.

\section{RESULTS AND DISCUSSION}

\section{Effect of Fuel Composition}

Concerning the fuel composition, it is believed that the aromatic content of the fuel has a major effect on the laminar burning velocity. The lower aromatic content leads to a maximum laminar burning velocity. Johnston et. al. [26] showed that the slower burning velocities of the fuels that have higher aromatic content are relating to the slower oxidation kinetics of resonance stabilized benzylic radicals which slow down the reaction rate. According to Radwan et. al. [19], fuels having the higher content of aromatics are expected to have low pyrolysis rate that leads to slow down of the combustion process. Comparison of data of different blends of boosted gasoline with those of commercial gasolines and iso-octane fuel shows that the laminar burning velocity of commercial gasolines and iso-octane is always greater than the boosted gasolines, as shown in Figures 4, 5 and 6. This appears to be due to lower aromatic 
contents of commercial gasolines compared to boosted fuels and zero aromatic content of iso-octane which considered one of the iso-paraffins group which have a higher pyrolysis and cracking rates compared to aromatic hydrocarbons. The commercial gasolines' burning velocity is more than iso-octane burning velocity, due to the chemical mechanism of combustion of commercial gasolines [27].

\section{Effect of Equivalence Ratio}

The influence of equivalence ratio on the laminar burning velocity of iso-octane, boosted gasolines RON (90, 92, 95 and 98) and Commercial gasolines RON (80, 90, 92 and 95 ) is presented in Figure 4 at initial pressure of 1 bar and an initial mixture temperature of $358 \mathrm{~K}$. The laminar burning velocity of iso-octane was composed for comparison. Generally, the data shows that the relation between the equivalence ratio and the burning velocity Leaning towards a bell shape. The burning velocity begins with low values in the lean mixture side and then rises as equivalence ratio increases until it reaches a maximum value at slightly rich mixture. at the rich mixture side, the laminar burning velocity begins to decrease until reaches a minimum value as the higher flammability limit is approached [16,22]. The maximum burning velocity is achieved at an equivalence ratio of 1.05 due to the high combustion temperature that results in a fast chemical reaction. Figure 4c shows a good agreement for burning velocity of commercial gasoline RON95 with those used by Dirrenberger [20]. Comparison of data with those of isooctane indicates that the laminar burning velocity of iso-octane is always greater than that of any of BGs and lower than that of any CGs. This appears to be due to no aromatic content of iso-octane which has a high pyrolysis and cracking rate and higher aromatic content of BGs comparing to CGs.

\section{Effect of Initial Mixture Temperature}

The effect of unburned mixture temperature on the laminar burning velocity of isooctane, boosted gasolines RON (90, 92, 95 and 98) and commercial gasolines RON $(90,92$ and 95$)$ is presented in Figure 5 at equivalence ratio and initial mixture pressure of 1 and 1 bar respectively. in general, the Figure shows that increasing the initial mixture temperature causes an increment in the laminar burning velocity. This can be illustrated according the Arrhenius equation:

$$
K=A T^{b} e^{-E / R T}
$$

where $\mathrm{K}$ is the reaction rate, $\mathrm{T}$ is the initial mixture temperature, $\mathrm{E}$ is the activation energy, $R$ is the universal gas constant and $A$ and $b$ are empirical constants. The equation shows that increasing the initial mixture temperature leads to increasing the reaction and cracking rates that tend to speed up the combustion process $[19,21]$.

\section{Effect of Initial Mixture Pressure}

The influence of initial mixture pressure on the laminar burning velocity of isooctane, boosted gasolines RON (90, 92, 95 and 98) and commercial gasolines RON 
(90, 92 and 95) is depicted in Figure 6. Measurements with varied unburned mixture pressure were carried out at a constant equivalence ratio and temperature of 1 and $358 \mathrm{~K}$ respectively. The Figure shows that as the initial mixture pressure increases the laminar burning velocity tends to decrease. If the pressure level at which flame is burning increases, the rate of the recombination reaction increases relative to the chain-branching reactions and therefore tends to lower the burning velocity as the recombination reaction dominates and destroys hydrogen atoms [25]. Generally, the laminar burning velocity of hydrocarbon-air mixtures can be expressed as:

$$
S_{L} \alpha P_{i}^{-n}
$$

where $\mathrm{n} \leq 0.5$ and negative $[19,21]$.

\section{CONCLUSIONS}

From the study conducted on isooctane and blends of jojoba bio-gasoline with basic gasoline fuels, the following conclusions may be drawn:

1. The iso-octane results and analytical correlation showed good agreement with other investigators, which gives confidence in the presently examined fuels results and their correlations.

2. The maximum value for laminar burning velocity for both iso-octane and blends of jojoba bio-gasoline with basic gasoline occurs at slightly rich mixture. Lower and higher flammability limits mixtures results in a lower burning velocity.

3. The laminar burning velocity for blends of jojoba bio-gasoline with basic gasoline fuels in general is lower than commercial gasolines and iso-octane. That may primarily be attributed to its high aromatic content.

4. The results showed that higher initial mixture temperatures lead to a higher laminar burning velocity.

5. Higher initial mixture pressures lead to a lower laminar burning velocity.

6. The best fit correlation that was extracted to predict the burning velocity of jojoba bio-gasoline and its blends with basic gasoline read:

$S_{L}=S_{L o} A\left(\frac{\varphi}{\varphi_{o}}\right)^{ \pm b}\left(\frac{T}{T_{o}}\right)^{m}\left(\frac{P}{P_{o}}\right)^{-n}$

where the constants $A, b, m$ and $n$ depend on the equivalence ratios range and fuel type.

7. Due to the lower burning velocity of BGs compared to CGs, higher turbulence intensity in the combustion chamber is needed.

\section{REFERENCES}

[1] J. Williams, "WTRG economics", Oil and Gas Journal,( 2003). 
[2] "Opportunities for Alternative Fuels and Fuel Additives: Technologies for Converting Waste into Fuel", Senate Interim Committee on Natural Resources: Report to 78th Legislature, (2002).

[3] C. Crawford, "Developing Bio-based Industries in Canada", Canadian New Uses Council (CANUC), June 1, (2001).

[4] M. Radwan, M., S. Elfeky, and O. Abu-Elyazeed, "An Investigation on Abnormal Combustion, Emissions and Performance of Novel Jojoba BioGasoline and Its Blends with Gasoline in a Spark-Ignition Engine", SAE Paper No.2012-01-1599-SAE2012 International Power trains, Fuels and Lubricants Meeting, Session: Alternative and Advanced Fuels (Part1 of 3) (FFL215),Malmo, Sweden ( 2012).

[5] W. Haas, and M. Mittelbach, "Detoxification Experiments with The Seed Oil from Jatropha Curcas L.," Industrial Crops and Products, an International Journal, Vol. 12, pp. 111-118, (2000).

[6] M.S. Radwan, "Preparation, development and characterization of Jojoba bio-fuels for I.C.engines", Internal report-ICE 1/2009, University of Helwan.

[7] H. Bayraktar, and O. Durgun, "Investigating the Effects of LPG on Spark Ignition Engine Combustion and Performance", Energy Conversion and Management, Vol. 46, pp. 2317-2333, (2005).

[8] T. Knorsch, A. Zackel, D. Mamaikin, L. Zigan, and M. Wensing, "Comparison of Different Gasoline Alternative Fuels in Terms of Laminar Burning Velocity at Increased Gas Temperatures and Exhaust Gas Recirculation Rates", Energy Fuels, Vol. 28, pp. 1446-1452, (2014).

[9] L. Sileghem, V.A. Alekseev, J. Vancoillie, K.M. Van Geem, E.J.K Nilsson, S. Verhelst and A.A. Konnov, "Laminar burning velocity of gasoline and the gasoline surrogate components iso-octane, n-heptane and toluene", Fuel, Vol. 112, pp. 355-365, (2013).

[10] G. Tian, G., R. Daniel, H. Li, H. Xu, S. Shuai and P. Richards, " Laminar Burning Velocities of 2,5-Dimethylfuran Compared with Ethanol and Gasoline", energy Fuels, Vol. 112, pp. 3898-3905, (2010).

[11] A.S. Huzayyin, H.A. Moneib, M.S. Shehatta and A.M.A. Attia, "Laminar Burning Velocity and Explosion Index of LPG-Air and Propane-Air Mixtures", Fuel, Vol. 87, pp. 39-57, (2008).

[12] J. Beeckmann and $\mathrm{H}$. Pitsch, " Investigation of the Laminar Burning Velocities of C1-C4 alcohols", the European Combustion Meeting, (2011).

[13] M.S. Radwan, S. Elfeky, I. Gizawy and F. Makar, "Jojoba Bio-Gasoline as an Octane Booster", Paper No. 125 , International Conference on Sustainable Energy and Environmental Protection (SEEP), Dublin Ireland, (2012).

[14] D. Bradley, R.A. Hicks, M. Lawes, C.G.W. Sheppard and R. Woolley, "The Measurement of Laminar Burning Velocities and Markstein Numbers for Isooctane- Air and Iso-octane-n-Heptane-Air Mixtures at Elevated Temperatures and Pressures in an Explosion Bomb", Combustion and Flame, Vol. 115, pp. 126-144, (1998).

[15] S. Jerzembeck, C. Glawe, J. Keppner and N. Peters, "Laminar Burning Velocities from Schlieren and Pressure History Measurements", 5th WSEAS International Conference on Fluid Mechanics (FLUIDS'08) Acapulco, Mexico, (2008). 
[16] M. Metghalchi and J.C. Keck, "Burning Velocities of Mixtures of Air With Methanol, Isooctane, and Indolene at High Pressure and Temperature", Combustion and Flame, Vol. 48, pp. 191-210, (1982).

[17] B. Lewis and G. von Elbe, "Combustion, Flames and Explosions of Gases", Third Edition, Academic Press, (1987).

[18] O.M.F. Elbahar, "Measurement of the Burning Velocity of Propane-Air Mixtures in a Constant-Volume Vessel with a Digital Signal-Processing Technique", Private Communication, (1992).

[19] M.S. Radwan, M. Ismail, M.Y. Selim, H. Saleh and H. Salem, "Laminar Burning Velocity of Some Coal Derived Fuels", Energy Sources, Vol. 23, pp. 345-361, (2001).

[20] P. Dirrenberger, A. Glaude, R. Bounaceur, H. Le Gall , A. Pires da Cruz, A.A. Konnov and F. Battin-Leclerc, "Laminar burning velocity of gasolines with addition of ethanol", Fuel, Vol. 115, pp. 162-169, (2014).

[21] M.S. Radwan, M.A. Ismail, S.M.S Elfeky, O.S.M. Abu-Elyazeed, "Jojoba methyl ester as a diesel fuel substitute: Preparation and characterization", Applied Thermal Engineering, Vol. 27, pp. 314-322, (2007).

[22] S.Y. Liao, D.M. Jiang, J. Gao, Z.H. Huang and Q. Cheng, "Measurements of Markstein Numbers and Laminar Burning Velocities for Liquefied Petroleum Gas-Air Mixtures”, Fuel, Vol. 83, pp. 1281-1288, (2004).

[23] O.L. Gülder, "Burning Velocities of Ethanol-Isooctane Blends", Combustion and Flame, Vol. 56, pp.261-268, (1984).

[24] J.P.J van Lipzig, E.J.K. Nilsson, L.P.H de Goey and A.A. Konnov, "Laminar Burning Velocities of n-Heptane, Iso-octane, Ethanol and their Binary and Tertiary Mixtures", Fuel, Vol. 90, pp. 2773-2781,( 2011).

[25] J. Warnatz, "Concentration, Pressure and Temperature Dependence of the Flame Velocity in Hydrogen-Oxygen-Nitrogen Mixtures", Combustion Science and Technology, Vol. 26, pp. 203-213, (1981).

[26] R. J. Johnston, J. T. Farrell, "Laminar Burning Velocities and Markstein Lengths of Aromatics at Elevated Temperature and Pressure", Proceedings of the Combustion Institute, Vol. 30, pp. 217-224, (2005).

[27] L. Cai, H. Pitsch, "Optimized Chemical Mechanism of Combustion of Gasoline Surrogate Fuels ", Combustion and Flame, Vol.162, pp. 16231637, (2015). 
Table 1. Chemical Properties for Jojoba Bio-Gasoline and Basic Gasoline.

\begin{tabular}{c|c|c}
\hline \hline $\begin{array}{c}\text { Chemical } \\
\text { Composition }\end{array}$ & $\begin{array}{c}\text { Bio- } \\
\text { Gasoline }\end{array}$ & $\begin{array}{c}\text { Basic Gasoline (RON80) } \\
{[14]}\end{array}$ \\
\hline $\mathrm{C} \%$ by weight & 86.13 & 85.67 \\
\hline $\mathrm{H}_{2} \%$ by weight & 13.86 & 11.33 \\
\hline $\mathrm{N}_{2} \%$ by weight & 0.002 & 1.3 \\
\hline $\mathrm{O}_{2} \%$ by weight & 0.001 & $\mathrm{NIL}$ \\
\hline \hline
\end{tabular}

Table 2. The characteristics of different blends of jojoba bio-gasoline in comparison with commercial gasoline at the various research octane numbers.

\begin{tabular}{|c|c|c|c|c|c|c|c|}
\hline $\mathrm{Cl}_{\text {Characteristic }}$ Fuel & $\begin{array}{c}\text { BG } \\
\text { RON90 }\end{array}$ & $\begin{array}{c}\text { CG } \\
\text { RON90 }\end{array}$ & $\begin{array}{c}\text { BG } \\
\text { RON92 }\end{array}$ & $\begin{array}{c}\text { CG } \\
\text { RON92 }\end{array}$ & $\begin{array}{c}\text { BG } \\
\text { RON95 }\end{array}$ & $\begin{array}{c}\mathrm{CG} \\
\text { RON95 }\end{array}$ & $\begin{array}{c}\mathrm{BG} \\
\mathrm{RON98}\end{array}$ \\
\hline Density @15.56 $\mathrm{C}$ & 0.7546 & 0.7406 & 0.7521 & 0.7518 & 0.7716 & 0.7419 & 0.7661 \\
\hline Specific gravity & 0.7553 & 0.7413 & 0.7528 & 0.7525 & 0.7724 & 0.7426 & 0.7669 \\
\hline API gravity @ 60F & 55.84 & 59.37 & 56.47 & 56.53 & 51.71 & 59.04 & 53.02 \\
\hline $\begin{array}{l}\text { Kinematic viscosity, } \\
\mathrm{cSt}, @ 40^{\circ} \mathrm{C}\end{array}$ & 0.53 & 0.50 & 0.51 & 0.54 & 0.54 & 0.50 & 0.52 \\
\hline Pour point, ${ }^{\circ} \mathrm{C}$ & $<-48$ & $<-48$ & $<-48$ & $<-48$ & $<-48$ & $<-48$ & $<-48$ \\
\hline Flash point, ${ }^{\circ} \mathrm{C}$ & $<45$ & $<45$ & $<45$ & $<45$ & $<45$ & $<45$ & $<45$ \\
\hline Calorific value, $\mathrm{kj} / \mathrm{kg}$ & 46565 & 46735 & 46585 & 45589 & 46314 & 46708 & 46398 \\
\hline $\begin{array}{l}\text { aromatic content, } \\
\text { vol\% }\end{array}$ & 35.6 & 29.4 & 36.4 & 27.9 & 38.5 & 29.5 & 38.8 \\
\hline Olefins content, vol\% & 4.0 & 1.9 & 2.2 & 1.2 & 1.5 & 1.3 & 2.1 \\
\hline $\begin{array}{l}\text { Saturates content, } \\
\text { vol\% }\end{array}$ & 60.4 & 68.7 & 61.4 & 70.9 & 65 & 69.2 & 59.1 \\
\hline
\end{tabular}




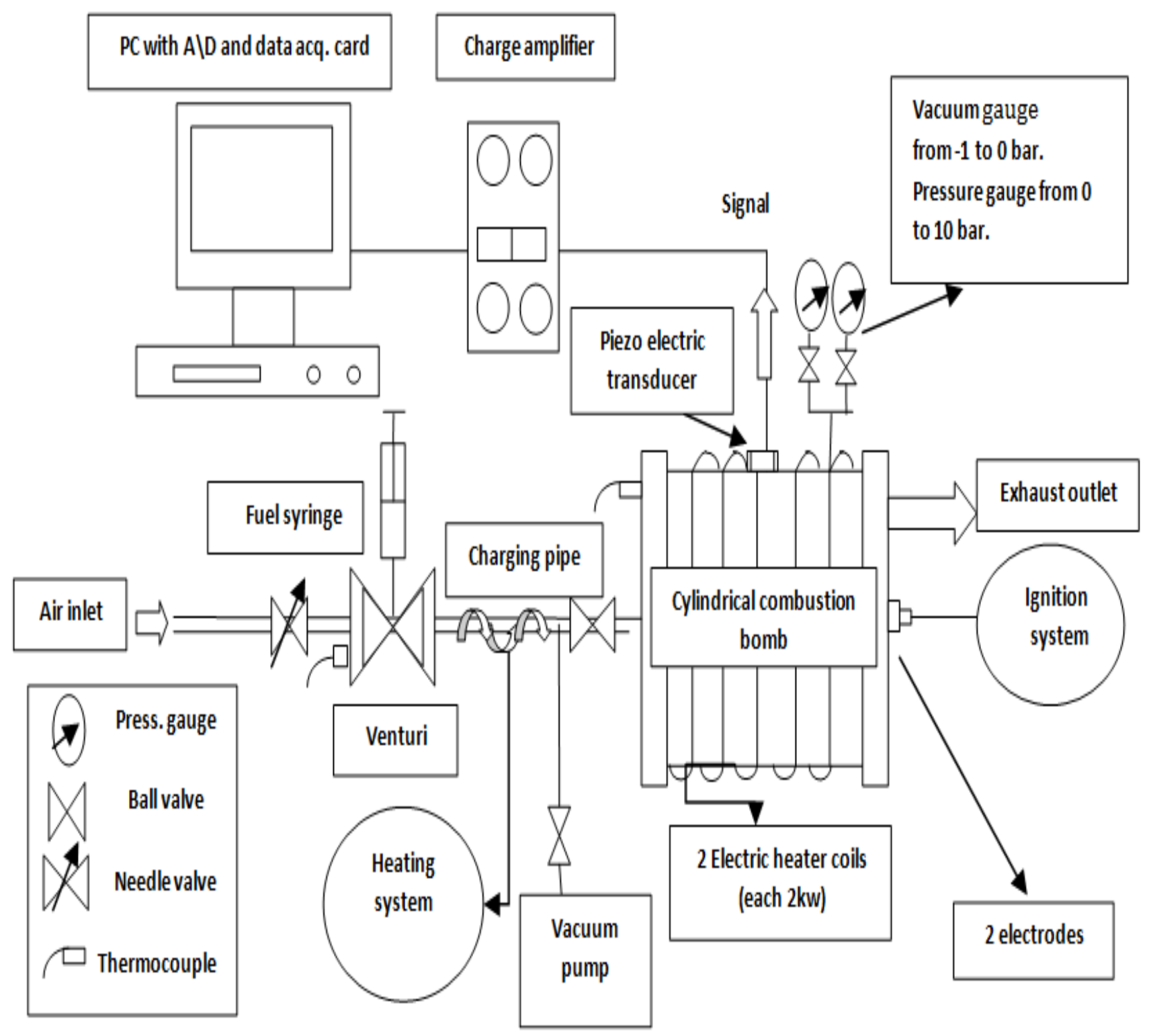

Fig. 1. Schematic layout of the experimental set-up. 


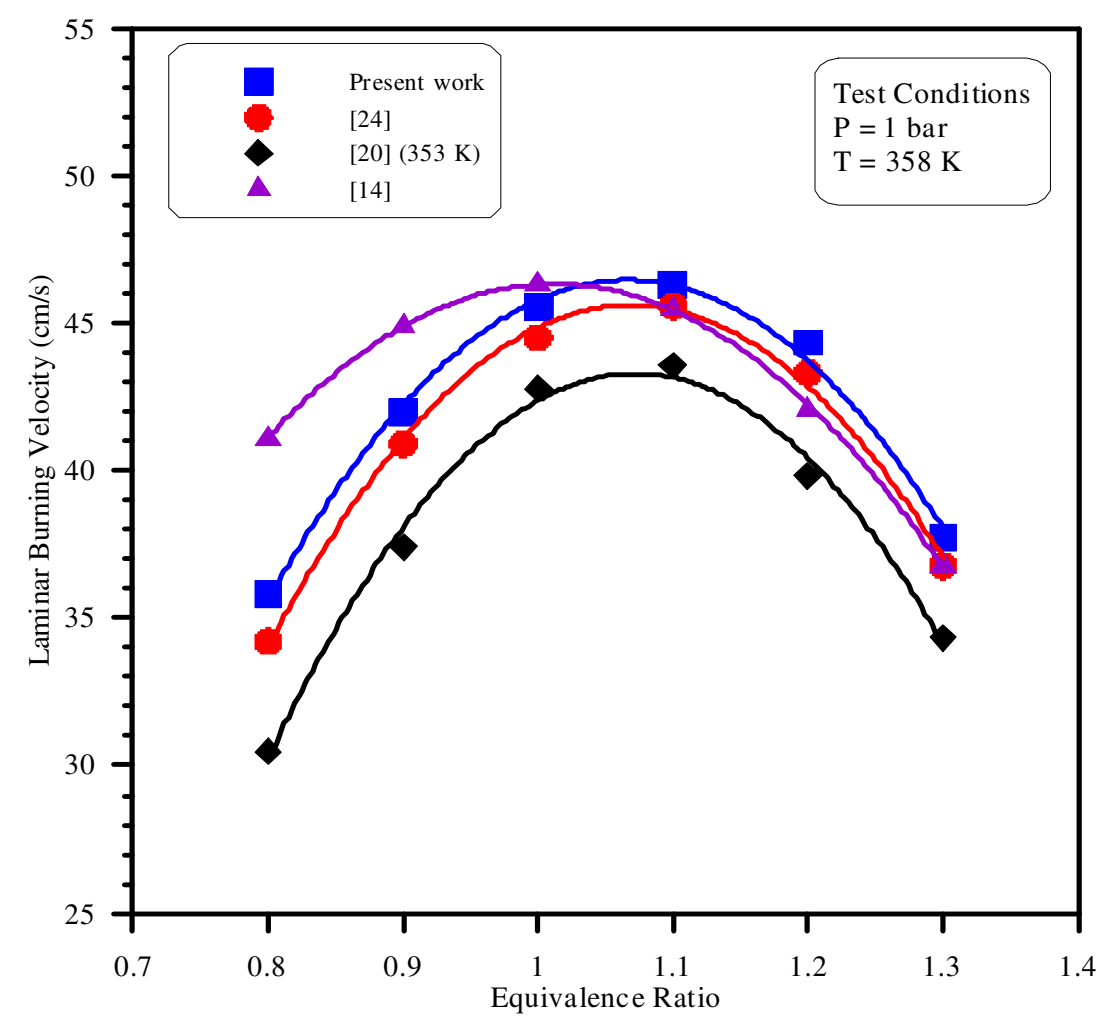

Fig. 2. Laminar burning velocity as a function of equivalence ratio for iso-octane.

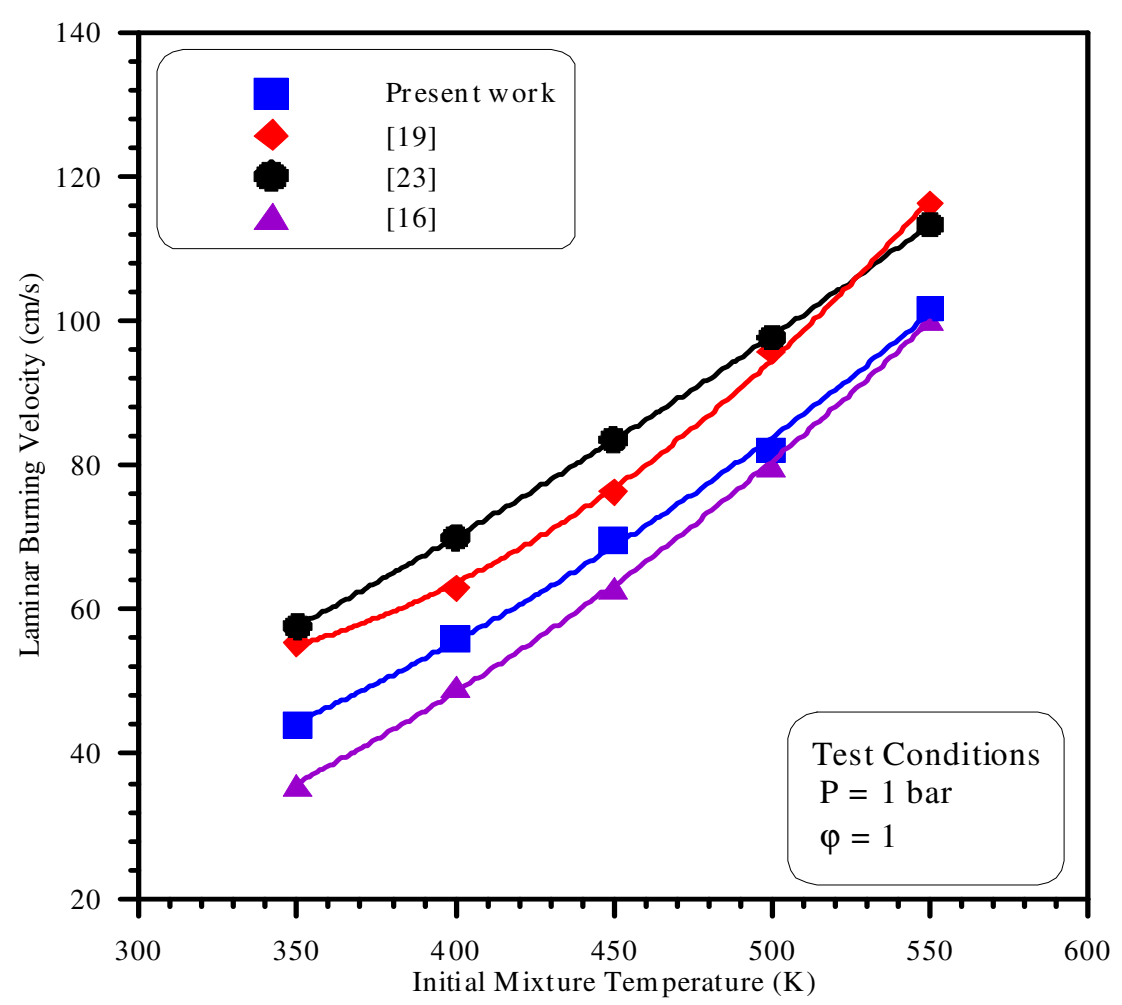

Fig. 3. Laminar burning velocity as a function of initial mixture temperature for isooctane. 

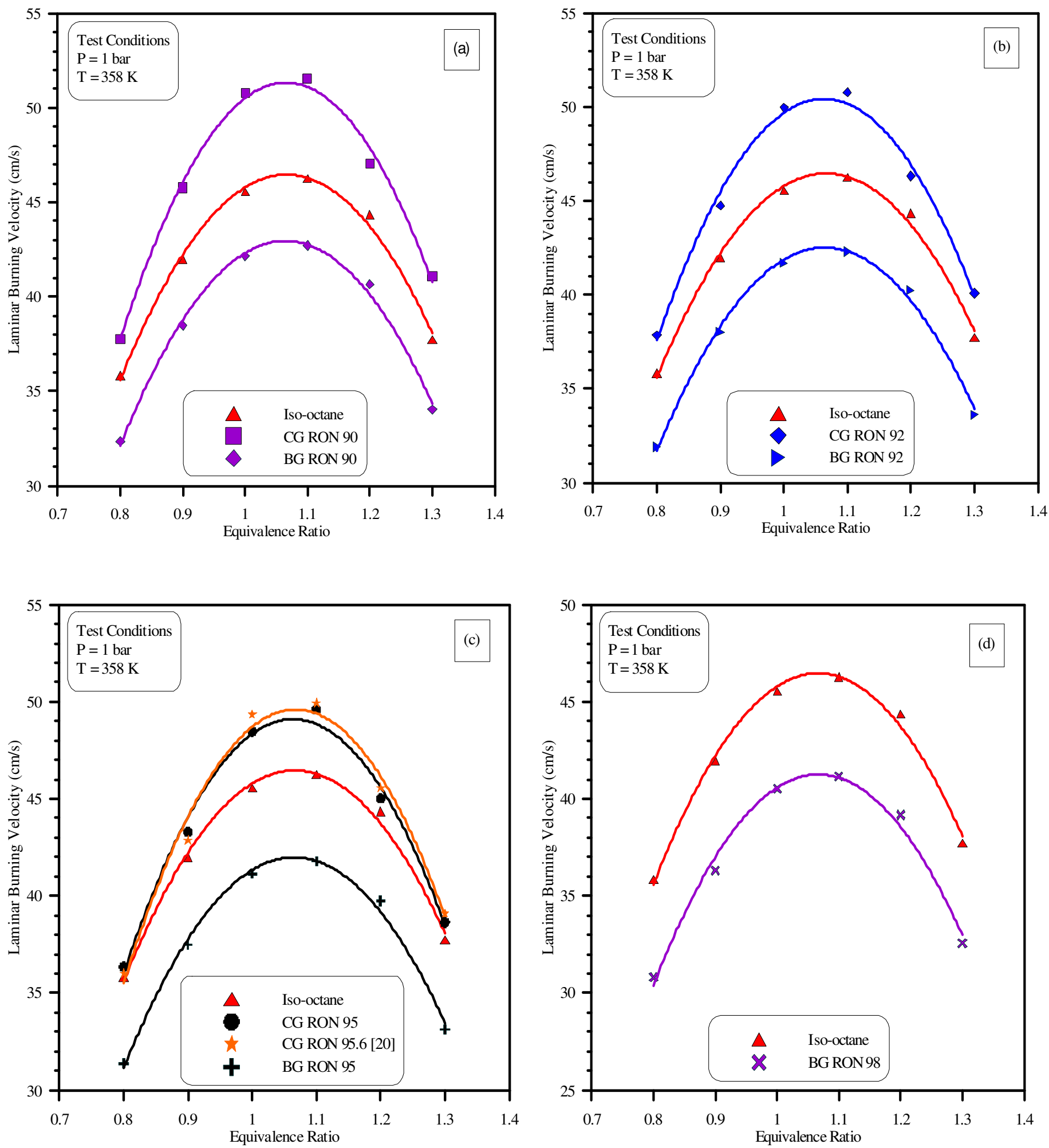

Fig. 4. The effect of equivalence ratio on the laminar burning velocity for: a. iso octane, BG RON 90 and CG RON 90, b. iso-octane, BG RON 92 and CG RON 92, c. iso-octane, BG RON 95 and CG RON 95, d. iso-octane, BG RON 98; at initial pressure of 1 bar and initial mixture temp. of $358 \mathrm{~K}$. 

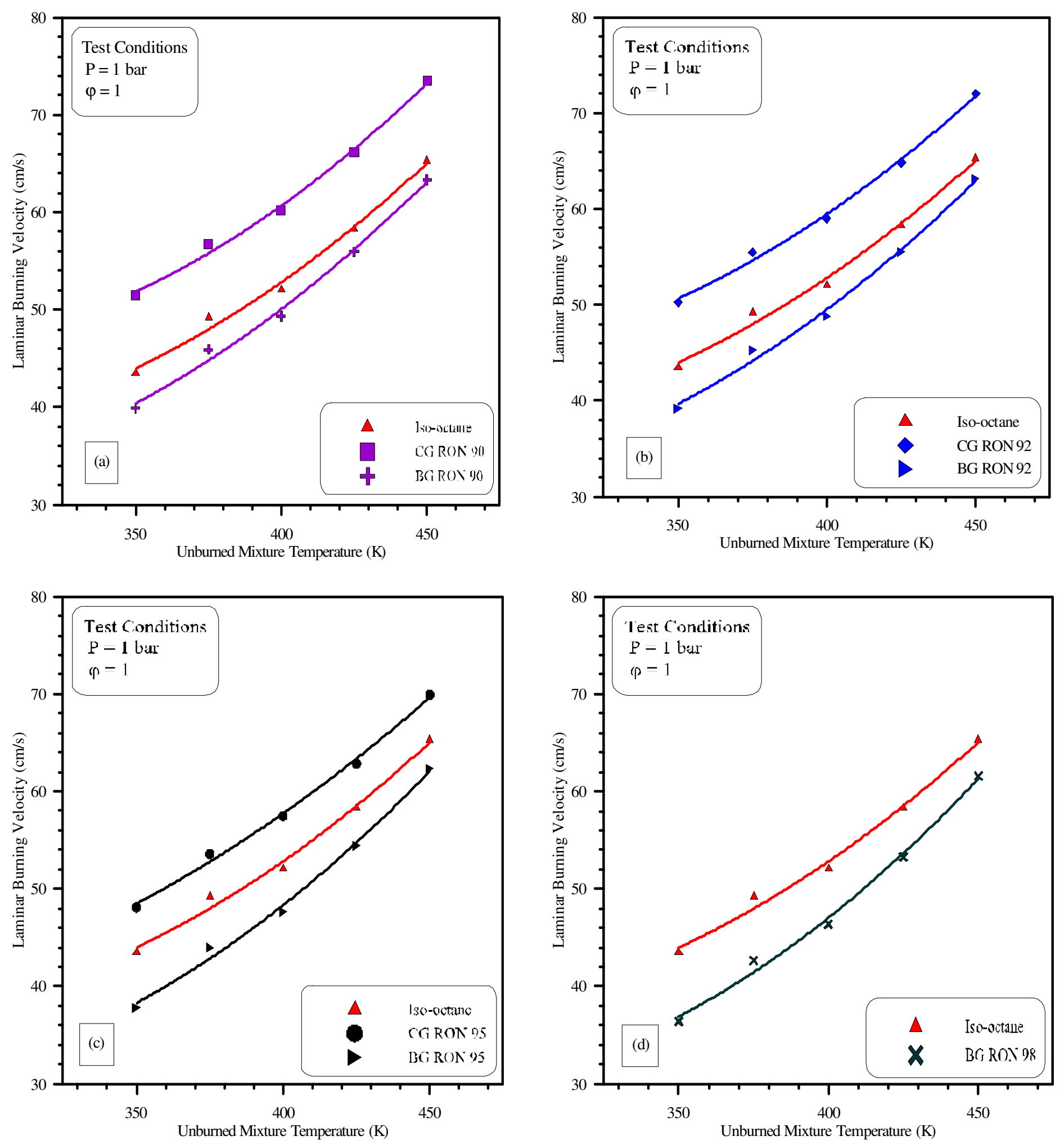

Fig. 5. The effect of the initial mixture temperature on the laminar burning velocity for: a. iso-octane, BG RON 90 and CG RON 90, b. iso-octane, BG RON 92 and CG RON 92, c. iso-octane, BG RON 95 and CG RON 95, d. iso-octane, BG RON 98 ; at initial pressure of 1 bar and equivalence ratio of 1 . 

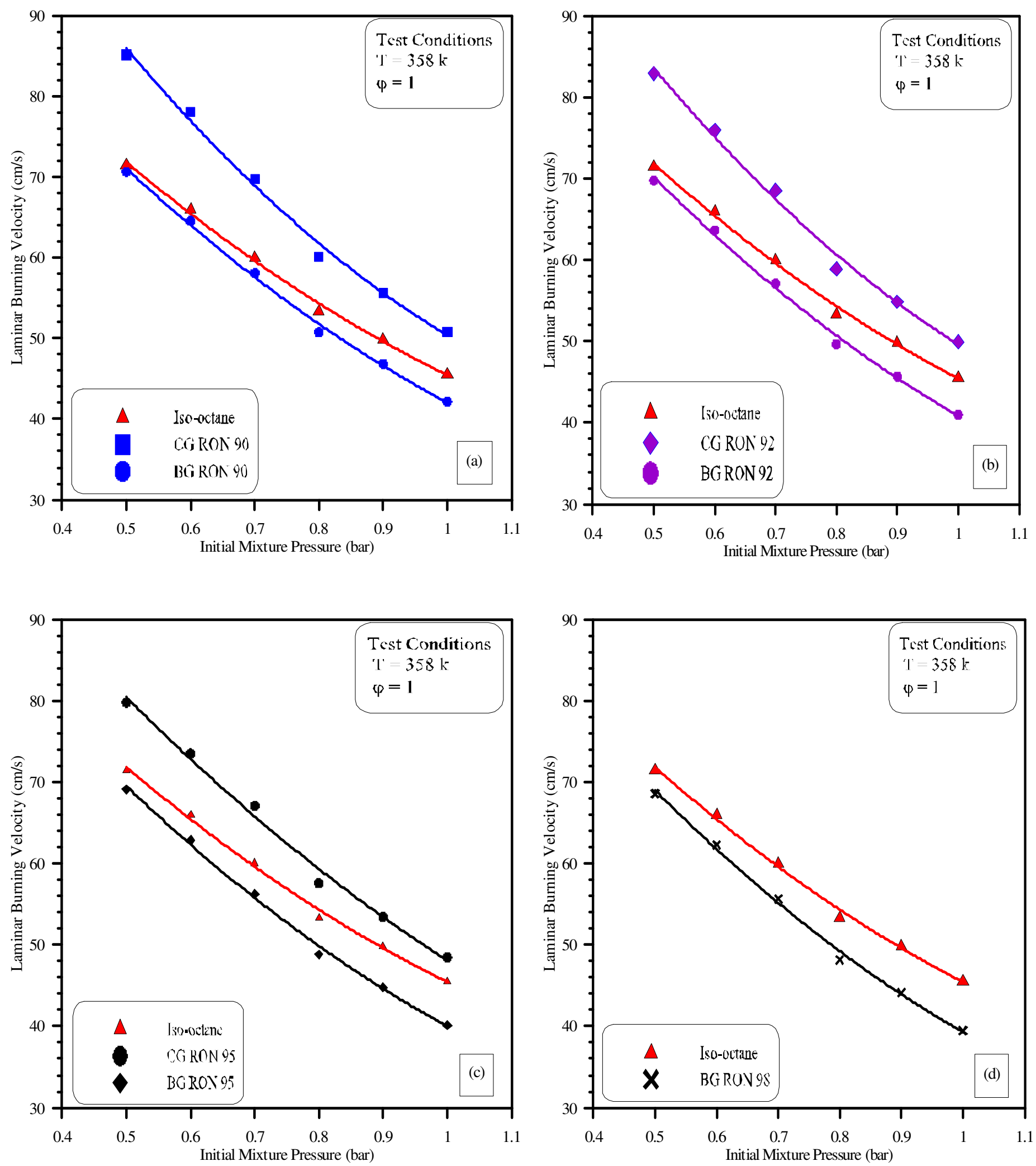

Fig. 6. The effect of the initial mixture pressure on the laminar burning velocity for: $a$. iso-octane, BG RON 90 and CG RON 90, b. iso-octane, BG RON 92 and CG RON 92, c. iso-octane, BG RON 95 and CG RON 95, d. iso-octane, BG RON 98 ; at initial temperature of $358 \mathrm{~K}$ and equivalence ratio of 1. 